Li T, Xu S, Zou Y, Chen X and Ikhumhen HO (2017) Modified mesoporous clinoptilolite characterization for non-biodegradable organic material removal. Emerging Materials Research 6(2): 314-321,
Emerging Materials Research Volume 6 Issue EMR2

Research article

Received 14/03/2016

Published online 20/09/2017

Keywords: adsorption/catalyst/transmission electron microscopy

\title{
Modified mesoporous clinoptilolite characterization for non-biodegradable organic material removal
}

\section{Tianxin $\mathrm{Li}^{\star}$}

Associate Professor, School of Civil and Environmental Engineering, University of Science and Technology Beijing, Beijing, China

\section{Shuiyang Xu MD}

Student, School of Civil and Environmental Engineering, University of Science and Technology Beijing, Beijing, China

\section{Yongcun Zou}

Associate Professor, State Key Laboratory of Inorganic Synthesis and

Preparative Chemistry, College of Chemistry, Jilin University, Changchun, China

\author{
Xiaohua Chen \\ Associate Professor, School of Civil and Environmental Engineering, \\ University of Science and Technology Beijing, Beijing, China \\ Harrison Odion Ikhumhen MD \\ Student, School of Civil and Environmental Engineering, University of \\ Science and Technology Beijing, Beijing, China
}

This paper reports the study of a novel mesoporous material modified from natural clinoptilolite (NC) through pore broadening and organic modification. In order to reveal purification capacity enhancement, micrographs obtained by performing high-resolution transmission electron microscopy on the materials were used to compare the inner structures of NC and mesoporous clinoptilolite (MC) at various magnifications. In MC, broader pores (from microporous to mesoporous) at the surface of $\mathrm{MC}$ and sublimation clouds of particles inside the pores and channels were found, while NC exhibited none of these features. The results obtained from energy-dispersive X-ray spectroscopy analysis indicate that the contents of impurities in MC were lesser than that of NC; the crystallinity of MC was also found to be more than that of NC. The decolorization rate of the MC material can reach up to $98.6 \%$, while that of $\mathrm{NC}$ is $\mathbf{8 7 \%}$, and the removal rates of MC's chemical oxygen demand as analyzed by the dichromate method $\left(C O D_{C r}\right)$ can reach $91.3 \%$, while the rate for NC is $56 \%$. The results indicate that the MC material has better adsorption with some mesoporous level $(2-50 \mathrm{~nm})$ on soluble organics, which is related to the pore diameter and the framework of the MC material from wastewater.

\section{Introduction}

Adsorption techniques are widely used to remove certain classes of pollutants from water, in particular those that are not easily biodegradable. Dyes represent one of the problematic groups. ${ }^{1}$ Natural zeolites are crystalline hydrated aluminosilicates with a framework structure containing pores occupied by water, alkali and alkaline earth cations. They are abundant and the resources are inexpensive. Due to their high cation-exchange ability as well molecular sieve properties, natural zeolites have been widely used as adsorbents in separation and purification processes in the past decades. $^{2}$

The use of natural zeolites in environmental applications is gaining new research interests mainly due to their properties and significant worldwide occurrence. Application of natural zeolites for water and wastewater treatment has been realized and is still a promising technique in environmental cleaning processes. In the past decades, utilization of natural zeolites has been focused on the use of ammonium and heavy metal removal due to the nature of ion exchange. ${ }^{3}$

Since the original discovery of zeolitic minerals in a volcanogenic sedimentary rock, zeolitic tuffs have been found in many areas of the world. In the past decades, natural zeolites have found a variety of applications in adsorption, catalysis, building industry, agriculture, soil remediation and energy. ${ }^{3}$ Elaiopoulos et $a l^{4}$ found that clinoptilolite can be used as a soil fertilizer to revegetate lands made barren by metal pollution. Natural zeolite needs to be modified to improve its ion-exchange and adsorption properties, as well as purity, before it can be used to remove ammonium compounds effectively. Traditionally, there are many different ways to prepare zeolite; these include physical methods, chemical methods (acids, alkali, salts of alkaline metals etc.) and a combination of the two. ${ }^{5}$ From the literature, there are several research studies on the modification of zeolites mainly focused on the adsorption of small polar organic molecules such as ammonia, ${ }^{5}$ phosphate, ${ }^{6}$ arsenic $^{7}$ and zirconium. ${ }^{8}$ However, only a few studies have focused on the adsorption of large non-biodegradable organic molecules using modified clinoptilolite on a mesoporous scale study and its theoretical explanation.

Therefore, in this paper, a novel mesoporous clinoptilolite (MC) material was obtained from natural clinoptilolite (NC). The details of the preparation procedure are discussed in the next section. Consequently, the MC material shows characteristics of both the 
original material and the loading ions with its microstructure evidently different from that of the original material. The experimental results ${ }^{9}$ show that the MC material can be employed as a high-concentration polluted-water-purifying material. In order to reveal the theory of the detailed microstructure of the material, analysis using high-resolution transmission electron microscopy (HR-TEM) was carried out. From the HR-TEM analysis, it was observed that the MC material has larger pores; through sublimation cloud of particles and energy-dispersive X-ray spectroscopy (EDS), it was observed that hexadecyltrimethylammonium bromide (CTMAB) had loaded the surface of the pores and channels instead of the surface of clinoptilolite. The inherent mechanism of how CTMAB contributed to the regularity of crystal was analyzed.

\section{Material and methods}

\subsection{Procedures for MC material preparation}

During the preparation of $\mathrm{MC}, \mathrm{NC}$ was used as silica-alumina source and framework of the raw material also known as natural zeolites. The zeolites were dispersed in $7 \%$ sulfuric acid $\left(\mathrm{H}_{2} \mathrm{SO}_{4}\right)$ solution, and the coal pulp concentration was $20 \%$, after which the solution was stirred for $1.5 \mathrm{~h}$ at $70^{\circ} \mathrm{C}$. After acid treatment ${ }^{10}$ of the solution, coal powder $(1 \mathrm{~g})$ with a particle size of $<43 \mu \mathrm{m}$ was added to the acid-treated zeolites $(9 \mathrm{~g})$ followed by heating in a muffle furnace at $250^{\circ} \mathrm{C}$ for $2 \mathrm{~h}^{11}$ After heating, the acid-treated zeolite was then cooled, thereby producing a porous slurry material. When cooled, $4 \mathrm{ml} / \mathrm{g}$ CTMAB solution, with a concentration of $5 \mathrm{~g} / \mathrm{l}$, was added into the resulting porous slurry material followed by additional stirring for $2 \mathrm{~h}$. After this exchange reaction, the material was washed with deionized water until a $\mathrm{pH}$ value of 7 was attained at $40^{\circ} \mathrm{C}$. The material was then dried in an oven for $2 \mathrm{~h}$ at $80^{\circ} \mathrm{C}$. After drying, the material was later rebaked at $230^{\circ} \mathrm{C}$ for $1.5 \mathrm{~h}$ by using the muffle furnace. ${ }^{12,13}$ This final process leads to obtaining the product material called novel MC material.

TEM images were taken with a Jeol 2010 high-resolution $(0.204 \mathrm{~nm})$ transmission electron microscope at $200 \mathrm{kV}$ at the University of Science and Technology, and the EDS facility attached to the transmission electron microscope was employed to analyze chemical composition.
The specimen of the MC material was prepared by the following method. One layer of the original materials was laid on a polished metal sheet; it was stably deposited onto the metal by using the ion deposition method. The metal sheet was milled from both sides until the two sides of the polished granulitic layers could be observed and eventually polished with the Precision Ion Polishing System for studying by TEM. The interior multiporous microstructures of the properly maintained granulitic membrane could also be observed by TEM. ${ }^{14,15}$

\subsection{Removal ability of apricot-shell-activated carbon, MC and NC material on wastewater treatment}

In order to ascertain the removal ability of the material for larger molecular soluble non-biodegradable organics, apricot-shellactivated carbon was used. The MC material and NC material, with two different concentrations of wastewater treatment statically, were implemented for obtaining the removal rate of the chemical oxygen demand as analyzed by the dichromate method $\left(\mathrm{COD}_{\mathrm{Cr}}\right)$ and decolorization ratio. The wastewater treatment system consisted of $250 \mathrm{~g}$ apricot-shell-activated carbon, MC material and $\mathrm{NC}$ material. Dye $(100 \mathrm{ml})$, whose chromaticity is 7400 times, was taken in a conical flask, along with wastewater. It was permitted to oscillate at a temperature $<30^{\circ} \mathrm{C}$ and 160 revolutions $/$ min for $2 \mathrm{~h}$. After stabilization, $\mathrm{COD}_{\mathrm{Cr}}$ removal rate and decolorization effect were measured. In order to compare the change in chemical composition, a gas chromatography-mass spectrometry (GC-MS) detection system was used for both raw wastewater and treated sample taken under the following conditions, as shown in Table 1.

\section{Results and discussion}

\subsection{Changes in mesoscopic morphology}

\subsubsection{Mesoscopic features}

The low-resolution transmission electron microscopy (LR-TEM) granulitic membrane images of $\mathrm{NC}$ and $\mathrm{MC}$ are shown in Figures 1(a) and 1(b), respectively.

Figure 1 reveals that the magnification of $\mathrm{NC}$ is too compact to observe the pores on the surface (under $\times 70000$ magnification). However, the numerous fractures and pores of MC can be easily

Table 1. GC-MS detection condition

\begin{tabular}{|c|c|c|c|c|}
\hline Sampling mode & $\begin{array}{c}\text { Inlet } \\
\text { temperature: }{ }^{\circ} \mathrm{C}\end{array}$ & Transmission line temperature: ${ }^{\circ} \mathrm{C}$ & Pressure before column: psi & $\begin{array}{l}\text { Flow rate of carrier } \\
\text { gas: } \mathrm{ml} / \mathrm{min}\end{array}$ \\
\hline Unsplit stream sampling & 250 & 280 & 8.8 & 0.609 \\
\hline Multiplier voltage: V & Scanning range & Column temperature & Ion source temperature: ${ }^{\circ} \mathrm{C}$ & $\begin{array}{l}\text { Chromatographic } \\
\text { column }\end{array}$ \\
\hline 1776 & $45-550$ & $\begin{array}{l}60^{\circ} \mathrm{C}(1 \mathrm{~min}) \text {, then } 10^{\circ} \mathrm{C} / \mathrm{min} \text {, following } \\
200 \sim 5^{\circ} \mathrm{C} / \mathrm{min} \text {, last, } 320^{\circ} \mathrm{C}(4 \mathrm{~min})\end{array}$ & 230 & $\begin{array}{c}\text { DB- }-530 \mathrm{~m}^{*} \\
0.25 \mathrm{~mm} \\
0.25 \mathrm{~mm}\end{array}$ \\
\hline
\end{tabular}

1 pound per square inch $(p s i)=6.89 \mathrm{kPa}$ 
Modified mesoporous clinoptilolite characterization for non-biodegradable

organic material removal

$\mathrm{Li}, \mathrm{Xu}$, Zou, Chen and Ikhumhen

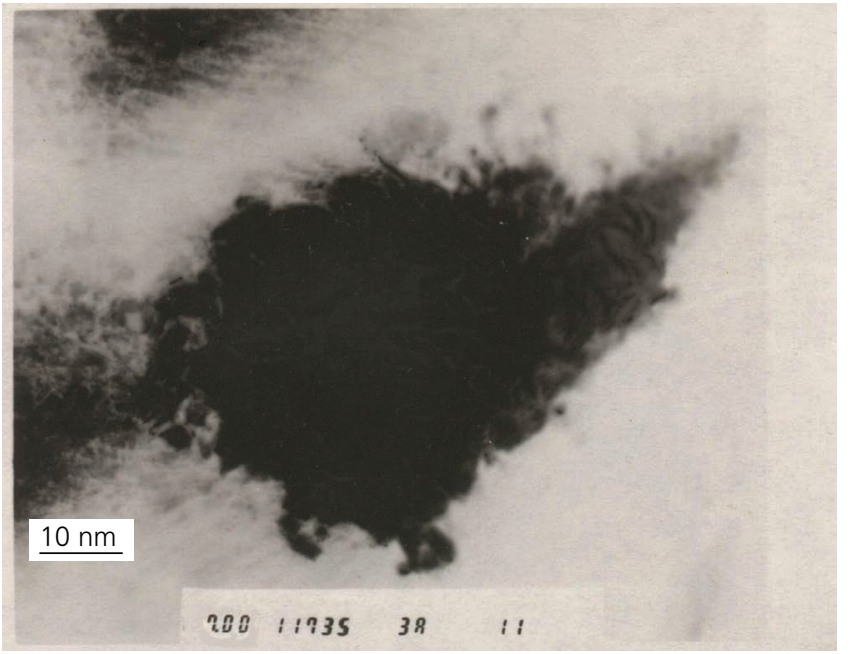

(a)

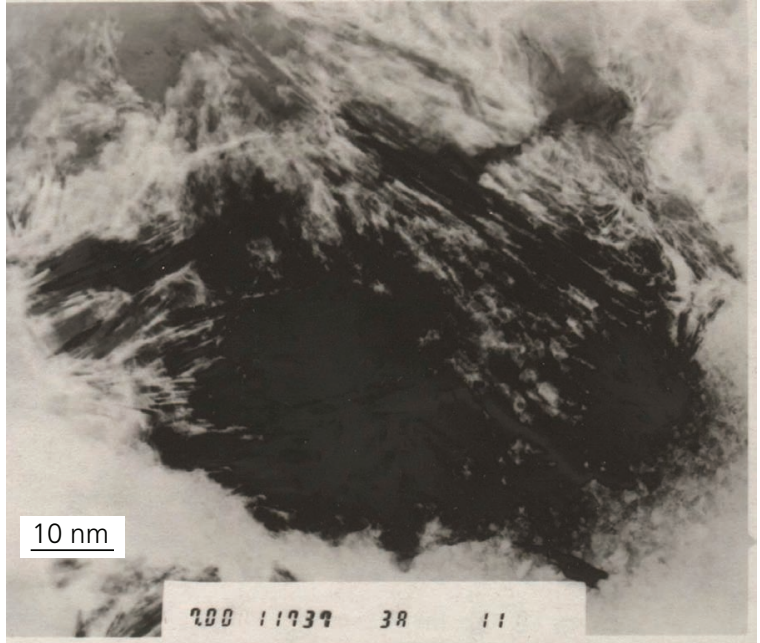

(b)

Figure 1. LR-TEM granulitic membrane images of (a) NC and (b) MC

observed in the interior granulitic membrane. The difference in the interior fractures and porous microstructures between the two materials indicates that MC excels in porosity compared with NC. This manufacturing procedure results in countless pores with diameters ranging from 2 to $20 \mathrm{~nm}$.

Figure 2 shows the HR-TEM images of the two materials. It is difficult to identify the tiny pores on the surface of $\mathrm{NC}$ under $\times 300000$ magnification. However, the tunnels in the MC were larger than the fractures and pores in the NC materials. The NC's original tiny and uniform porous structures turned into more porous, long and narrow fractured structures, indicating that $\mathrm{MC}$ exhibits various pore diameters and its interior structures are rearranged.

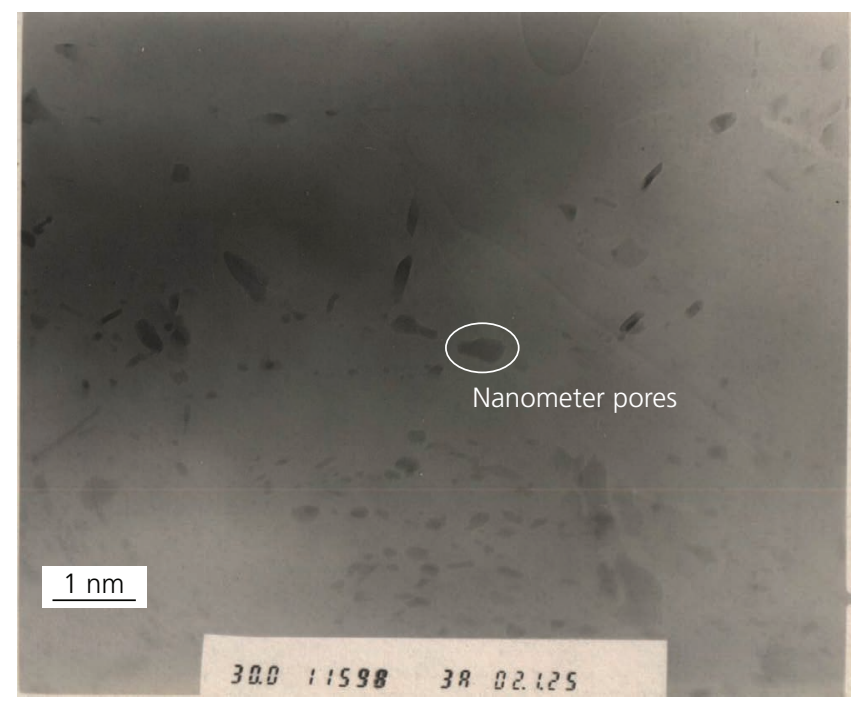

(a)

\subsection{Analysis of the phenomenon of sublimation cloud of particles}

Figure 3(a) shows the original channel's surface of MC material; Figure 3(b) shows the channel's surface of MC material with highenergy electron beam illumination of TEM. A sublimation cloud of particles occurred immediately but disappeared quickly. The sublimation cloud of particles was caused by two reasons: First, in the lattice production procedure, the grain boundary had flaws and partial lattice dislocation and rearrangement was generated in the interior lattice, resulting in the substructure in the region close to the boundary; thus, instant sublimation cloud of particles occurred because of the high-energy electron beam. Liu et al. ${ }^{16}$ pointed out that due to thermal vibrations, there seems to be a defect form

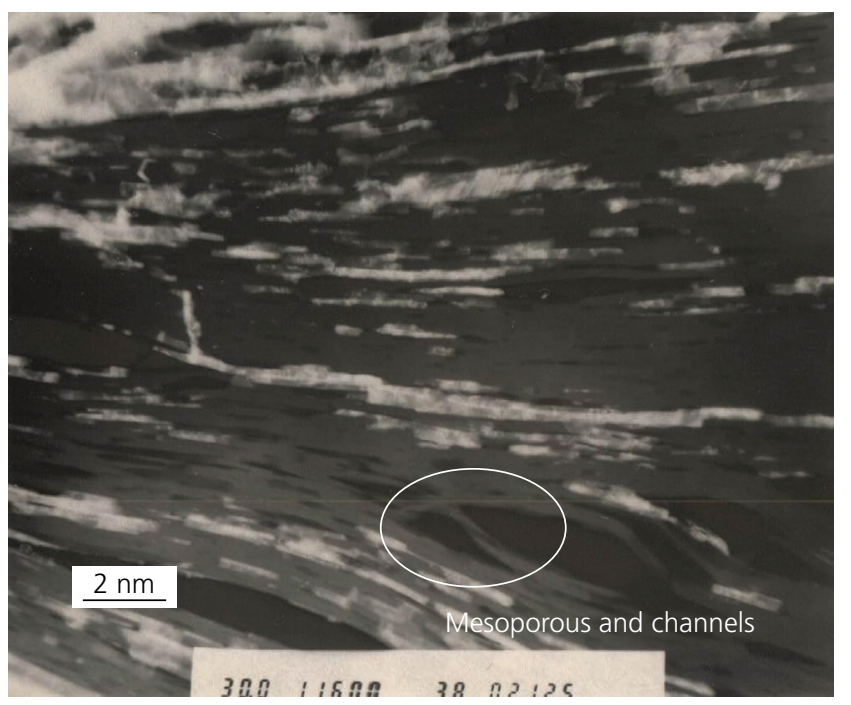

(b)

Figure 2. HR-TEM granulitic membrane images of (a) NC and (b) MC 


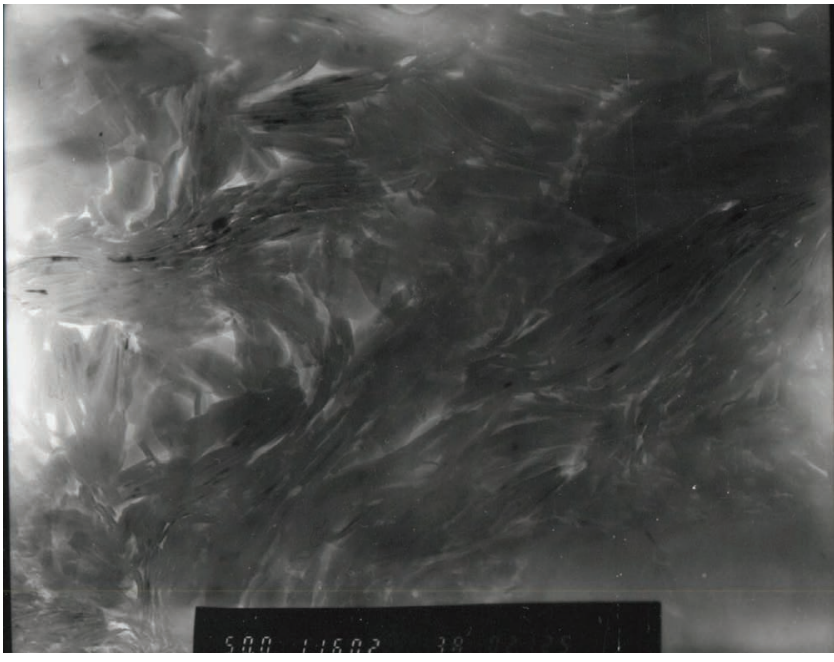

(a)

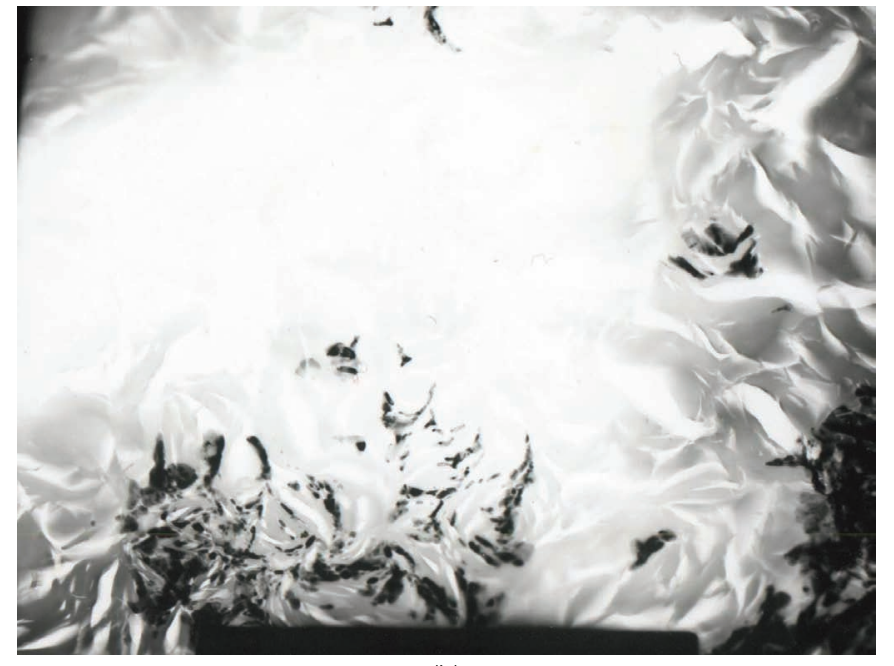

(b)

Figure 3. Sublimation clouds of particles on the channel's surface of MC

when an atom or ion leaves its place in the lattice, creating a vacancy and becoming interstitial by lodging in a nearby location not regularly occupied by an atom. The conditions of the material production procedure in this research are based on the Frenkel defect theory; therefore, the defect can exist in the final product that can produce slight lattice dislocation and rearrangement. The second reason is that the interior organic ions in the $\mathrm{MC}$ can be activated instantly due to the high-energy electron beam; these ions can capture the anions in the air and then be sublimed at the surface, resulting in a dynamic sublimation group similar to the sublimation cloud of particles. The organic and inorganic component transformation of a mesoporous composite material, in the preparation process, was analyzed based on the infrared spectrograms and X-ray diffraction patterns of NC and MC. The change in components and their ratios in the material were deduced to judge the crystal lattice change in organic ion-exchange products. A transformation mechanism of components in the material was proposed according to Fourier transform infrared (FTIR) analysis, X-ray analysis and TEM analysis. ${ }^{17}$

\subsection{Analysis of diffraction mottle}

Figure 4 shows that before the dislocation phenomenon disappeared at the surface of the material, an extremely regular diffraction mottle could be generated due to the quickly escaped lattice diffraction mottle. The left image in Figure 4 shows a regular polycrystalline electron diffraction pattern, and the image on the right shows the diffraction mottle of the granular methane surface. The polycrystalline electron diffraction pattern, similar to an X-ray diffraction pattern, is composed of multiradius and multibrightness concentric rings. The brightest mottle at the center is the transmission mottle, while the multiradius and multibrightness rings represent the diffraction mottles of various isosurfaces $\left\{h_{1} k_{1} l_{1}\right\}$ and $\left\{h_{2} k_{2} l_{2}\right\}$. The indices of the crystal face of the interior ring are simple integers, while those of the periphery rings are large integers. The polycrystal is composed of random crystalline grains. When the isoplane groups $\{k h l\}$ of various random small grains are in accordance with the diffraction conditions, a conical surface with the axis based on the incident beam and with a $2 \theta$ angle is generated, the intersection line of which with the photographic plate can be regarded as a circle with radius $(R): R=L \lambda d$. Thus, the circular pattern of polycrystalline diffraction turned out to be a superposition of different single crystal diffraction mottles, and the crystalline plane groups with different diameters can generate various polycrystalline diffraction patterns that are composed of multiradius concentric circles. The polycrystalline material is composed of crystal grains and grain boundaries. The grain boundary is the intersection plane of two multidirectional adjacent grains, where the array of particles is irregular; therefore, the grain boundary exhibits the general characteristics of a lattice defect. Read established the theory of small-angle-of-misfit grain boundaries ${ }^{18}$; the small angle tilt boundary consists of edge dislocation and shears ordinary array along the grain boundaries. As the grain boundaries are anisotropic, it is widely recognized that grain boundaries are ordered structural levels that are well proved by Read's smallangle-of-misfit grain boundaries model, which indicates that the neighbor grains are partially fit regular sectors depending on the geometrical characteristics of grain boundaries.

Therefore, a further conclusion can be drawn that grain lattice change occurs during the material production procedure according to the polycrystalline electron diffraction patterns. Two reasons can account for this variance: First, as abundant potassium $\left(\mathrm{K}^{+}\right)$, sodium $\left(\mathrm{Na}^{+}\right)$and calcium $\left(\mathrm{Ca}^{2+}\right)$ exist in the natural mesoporous zeolite pores, some of the anions can enter the pores and the trace amount of magnesium $\left(\mathrm{Mg}^{2+}\right)$ or aluminum $\left(\mathrm{Al}^{3+}\right)$ ions can be exchanged. The dissolved magnesium or aluminum ions can cause partly distortion of the lattice, leading to increasing lattice 

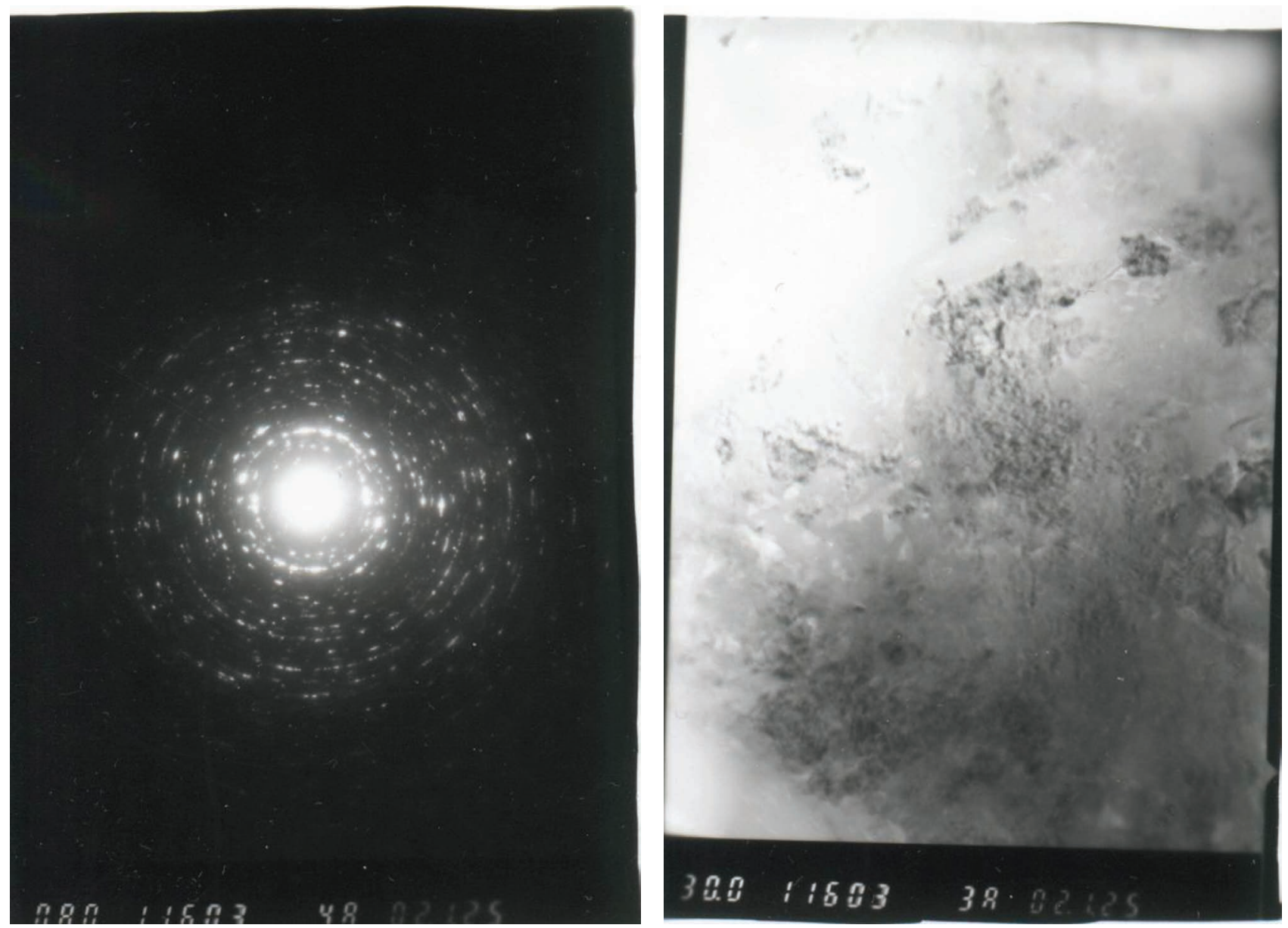

Figure 4. Diffraction images of mesoporous composite granulitic membranes

defects; meanwhile, the impurities in the pores can be dissolved and removed, resulting in smoothening of the pores. Therefore, in the additive roasting process, the silicon in the additive (primarily composed of silicon and carbon) can partly replace magnesium and aluminum or be included in the nanocages of the original material framework, resulting in the negative framework charge forming the significant Brønsted acid site that can strongly activate the microregion and lead to partial rearrangement. ${ }^{19}$ The rearrangement causes the microregion to be highly ordered on the microscopic scale, which results in forming abundant likemicrocrystals where the grain boundary phenomenon occurs, accounting for particular polycrystalline electron diffraction patterns. ${ }^{20}$ Nevertheless, if illuminated by high-energy electron beams, the diffraction patterns will disappear with the reexcitation, as this crystal formation is not stable enough.

\subsection{Analysis of composition}

EDS was employed to analyze the composition and content variances of the inorganic elements. It is one of the electron probe $\mathrm{X}$-ray microanalysis technologies and can be used to analyze the energy spectrum of the material at specific regions. In the TEM analysis, EDS was used to detect the inorganic element composition and content of the two materials ( $\mathrm{MC}$ and $\mathrm{NC}$ ); elements with atomic numbers below 11 are undetectable with EDS. The element components of the two materials are summarized in Table 2. The table shows that the content of the MC material decreased compared with that of the $\mathrm{NC}$ material, indicating the effectiveness of impurity removal in the pores during the production procedure. In the meantime, the silicon content increased apparently, while the magnesium, aluminum and calcium contents decreased to some extent in the MC material.

Table 2 shows the variance in element content, indicating that after treatment, magnesium, aluminum and calcium decreased tremendously. The intensity of the highly active element, aluminum, exhibited a decrease in the diffraction peak relative strength of EDS from $23 \cdot 151$ to $7 \cdot 714$ counts/s due to ion exchange. Meanwhile, the decrease in impure elements can improve the content of inert silicon, which contributed to the regularity of the crystal. Therefore, these data can reflect the changes in the content of the element consisting of the material changes and crystal phase changes through the production, which can be elucidated by two reasons: 
Table 2. Element components of NC and MC materials

\begin{tabular}{lcrrr} 
Element & Sample & \multicolumn{1}{c}{ CPS } & wt $\%$ & \multicolumn{1}{c}{ at $\%$} \\
Magnesium & NC material & 3.654 & 3.958 & 4.577 \\
& MC material & 1.333 & 4.116 & 4.730 \\
Aluminum & NC material & 23.151 & 20.990 & 21.413 \\
\multirow{2}{*}{ Silicon } & MC material & 7.714 & 19.515 & 20.207 \\
\multirow{2}{*}{ Calcium } & NC material & 33.988 & 70.290 & 70.361 \\
& MC material & 92.863 & 73.319 & 72.936 \\
& NC material & 7.270 & 5.202 & 3.649 \\
& MC material & 1.496 & 3.051 & 2.127
\end{tabular}

CPS, diffraction peak relative strength of EDS: counts/s

first, the decrease in impurity-like elements such as calcium can demonstrate the effectiveness of impurity removal and pore creation in the former two stages, and second, the increase in silicon indicates not only the reaction of additives with materials in the cauterization process but also the material crystal phase change that is substantially the consequence of the acid-base reaction. The Lewis acid-base theory demonstrates that an acid accepts electrons while a base donates electrons. Essentially, the acid-base reaction produces acid-base complexes by forming coordination bonds. In this research, the $\mathrm{M}$ in the zeolite acts as a Lewis acid, while the framework $\left[\mathrm{AlO}_{4}\right]$ serves as a Lewis base, indicating the new composite characters of different lattice positions, so that different ions or ionic compounds can make positioning bonding in zeolite. The nucleophilic or Lewis base can bond with the cation of the Lewis acid in the zeolite, while the electrophilic or Lewis base can bond with the framework anion. The primary coordination configuration is shown in Figure 5.

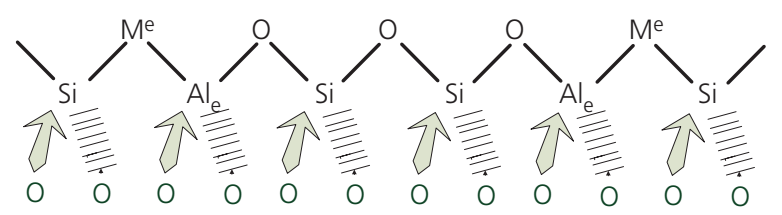

Figure 5. Coordination configuration of tetrahedral unit cell, framework cation and foreign ion in zeolite
The interaction of ligand and guest of zeolite results in some bonding reaction between the Brønsted acid and metal cation, which can activate the guest through the directional reaction with the cations outside the framework. A series of special substances produced in this reaction can contribute to the outstanding characteristics of zeolite. ${ }^{21}$

\subsection{Feasibility of MC}

This MC material offers the possibility of an efficient removal of some larger molecular soluble non-biodegradable organics. For high-concentration organic dyestuff wastewater, in which the $\mathrm{COD}_{\mathrm{Cr}}$ is $3040 \mathrm{mg} / \mathrm{l}$ and the chroma is 7400 times, the decolorization rate of the MC material can reach up to $98.6 \%$, with the decolorization rate of $\mathrm{NC}$ being $87 \%$. The adsorption capacity of the material is $4.573538 \mathrm{mg}$ dye $/ \mathrm{g}$ material, and the removal rates of $\mathrm{COD}_{\mathrm{Cr}}$ can reach $91 \cdot 3 \%$ for $\mathrm{MC}$, and the rates for $\mathrm{NC}$ are $56 \%$. The effect of the MC material is better than that of high-quality apricot-shell-activated carbon. ${ }^{12}$ The full-scan spectra of raw and treated wastewater samples are shown in Figures 6(a) and 6(b). The results of the qualitative analysis, as obtained from the GC-MS full-scan spectra, are shown in Table 3.

From the results in Table 3, it is observed that the MC material is effective for most soluble organics. After treatments with the material, the substances left in the water were diisobutyl phthalate $\left(\mathrm{C}_{16} \mathrm{H}_{22} \mathrm{O}_{4}\right)$ and phthalic acid mono-2-ethylhexyl ester $\left(\mathrm{C}_{16} \mathrm{H}_{22} \mathrm{O}_{4}\right)$, and their sizes were bigger than the mesoporous hole. The results also show that $\mathrm{MC}$ is effective for soluble organics with a molecular size of $<2-50 \mathrm{~nm}$. It can be observed that the MC materials are unable to remove the organics that are larger than $50 \mathrm{~nm}$.

\section{Conclusions}

The present investigation showed that the broader pore sizes of the MC material results from the pore-expanding method, which changes the pore diameters and structures. The structure of the pores alters from microporous to mesoporous; therefore, the obtained MC material has a broad range of pore diameters.

Table 3. Matching rates of raw wastewater and treated waters organic material

\begin{tabular}{llccc} 
& Name of organic & Molecular formula & \multicolumn{2}{c}{ NIST standard library search matching rate: \% } \\
\cline { 3 - 5 } & & & Raw wastewater & Treated water \\
\hline 1 & 1-Hydroxy-2-methoxybenzene & $\mathrm{C}_{7} \mathrm{H}_{8} \mathrm{O}_{2}$ & - \\
2 & 4-Ethyl-2-methoxyphenol & $\mathrm{C}_{9} \mathrm{H}_{12} \mathrm{O}_{2}$ & 95 & - \\
3 & 2,6-Dimethoxyphenol & $\mathrm{C}_{8} \mathrm{H}_{10} \mathrm{O}_{3}$ & 94 & - \\
4 & Dimethyl phthalate & $\mathrm{C}_{10} \mathrm{H}_{10} \mathrm{O}_{4}$ & 60 & - \\
5 & Diisobutyl succinate & $\mathrm{C}_{12} \mathrm{H}_{22} \mathrm{O}_{4}$ & 91 & - \\
6 & Acetosyringone & $\mathrm{HOC}_{6} \mathrm{H}_{2}\left(\mathrm{OCH}_{3}\right)_{2} \mathrm{COCH}_{3}$ & 72 & - \\
7 & Diisobutyl phthalate & $\mathrm{C}_{16} \mathrm{H}_{22} \mathrm{O}_{4}$ & 97 & - \\
8 & 1,2-Benzenedicarboxylic & $\mathrm{C}_{20} \mathrm{H}_{30} \mathrm{O}_{4}$ & 83 & - \\
9 & 1,2-Benzenedicarboxylic acid, dipentyl ester & $\mathrm{C}_{18} \mathrm{H}_{26} \mathrm{O}_{4}$ & 83 & - \\
10 & Heptafluorobutyric acid hexadecyl ester & $\mathrm{C}_{20} \mathrm{H}_{33} \mathrm{~F}_{7} \mathrm{O}_{2}$ & 64 & - \\
11 & Phthalic acid mono-2-ethylhexyl ester & $\mathrm{C}_{16} \mathrm{H}_{22} \mathrm{O}_{4}$ & 83 & 91
\end{tabular}

NIST, National Institute of Standards and Technology 


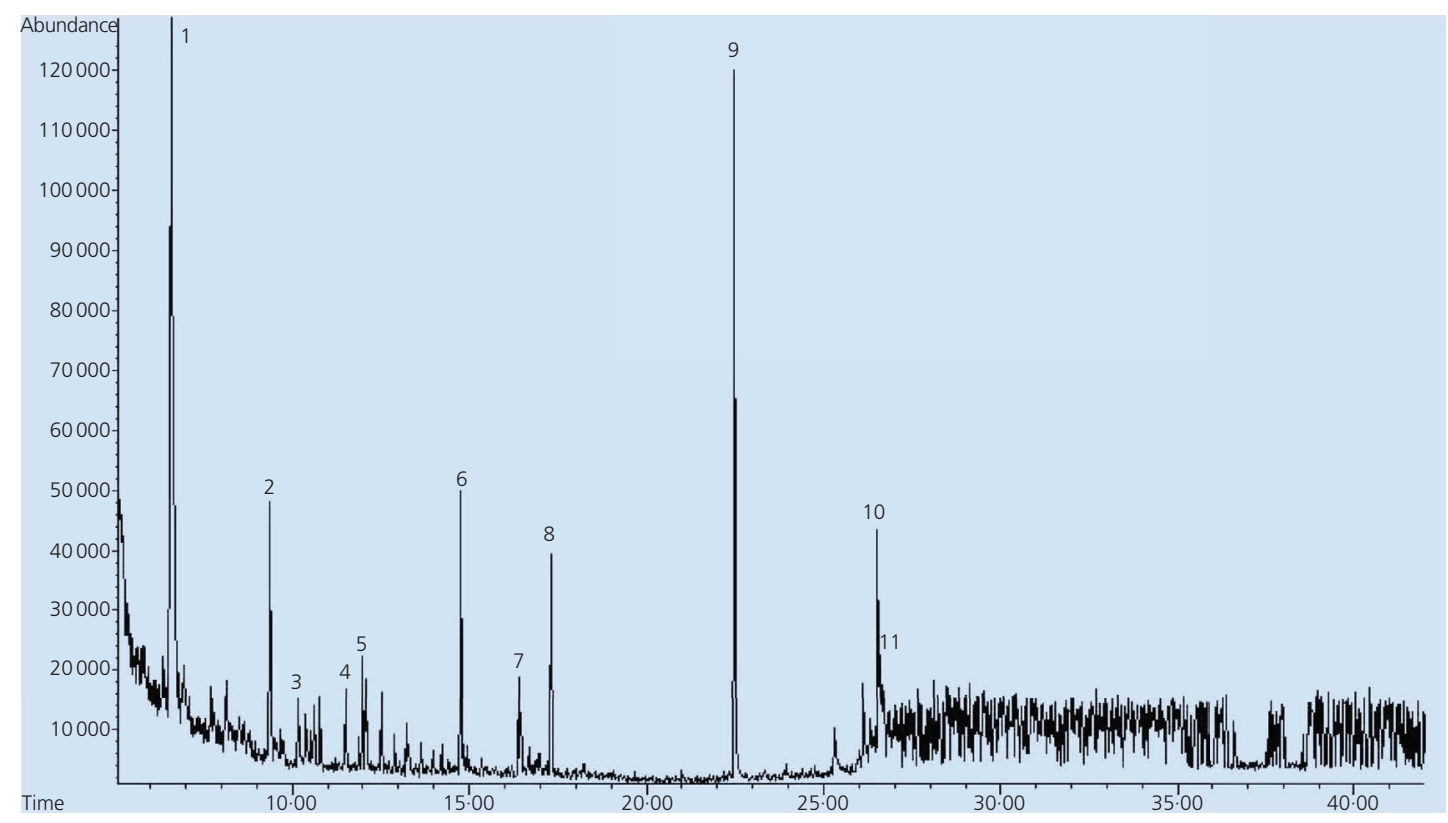

(a)

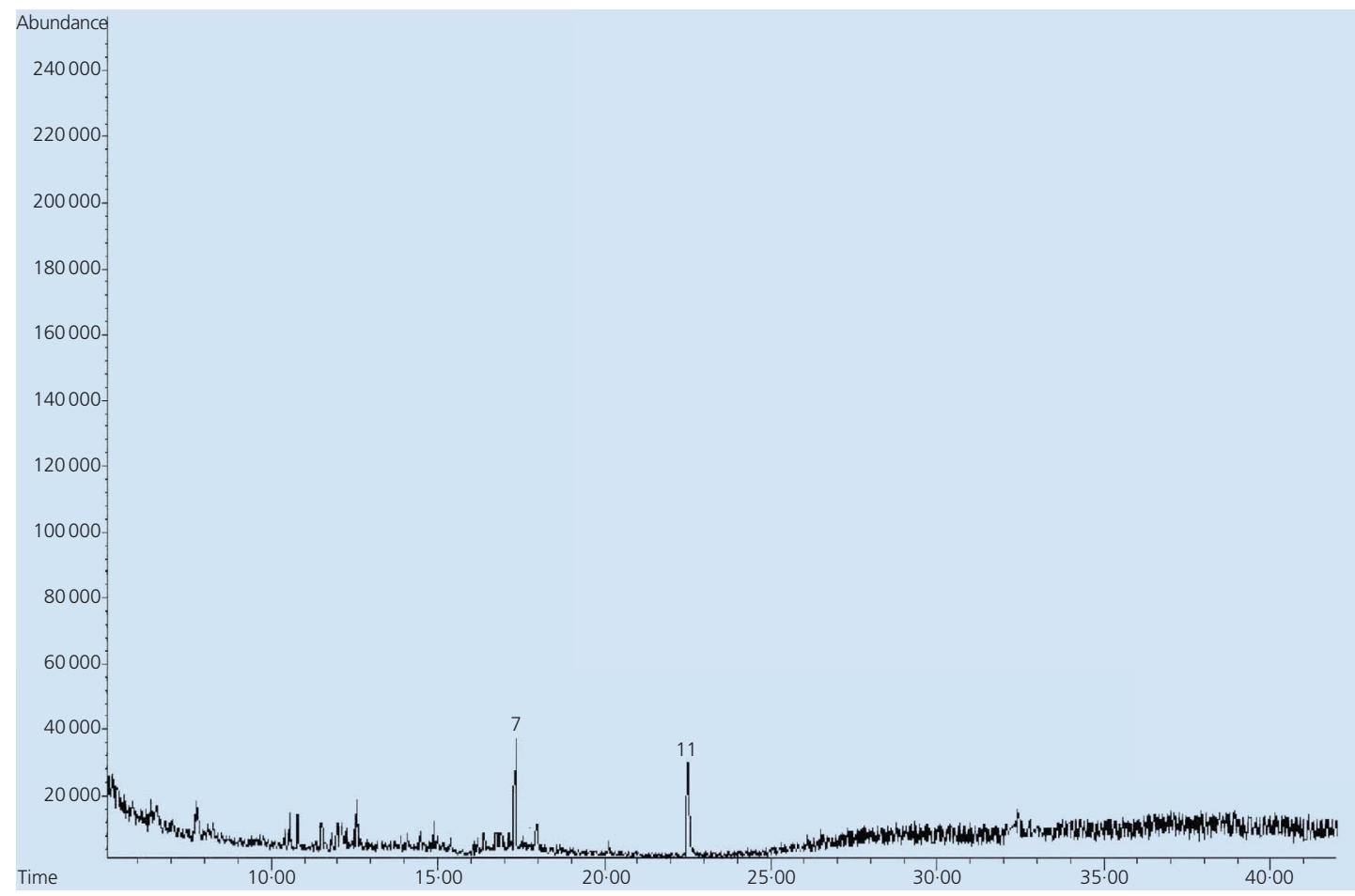

(b)

Figure 6. Full spectra of (a) raw wastewater and (b) treated wastewater

The diffraction mottle and EDS analysis shows that CTMAB and calcination can enhance crystallinity in the production procedure, which produces the lattice-defect-like grain boundaries and regional dislocation and rearrangement, leading to abundant partly regular structures; therefore, this production process can enhance the surface activation of pores and channels.
The EDS analysis shows that there is an alteration of the MC material after treatment which consists of the lattice change, demonstrating the mechanism of the production approach: The bonding reaction occurs between the Brønsted acid site and the metal cation of the ligand and guest of zeolite, and the guest is activated by the directional interaction of the cations 
Modified mesoporous clinoptilolite characterization for non-biodegradable organic material removal $\mathrm{Li}, \mathrm{Xu}$, Zou, Chen and Ikhumhen outside the framework, resulting in some specific function of the product.

The MC material is effective for most soluble organics, which have molecular sizes of $2-50 \mathrm{~nm}$. If the organics are larger than $50 \mathrm{~nm}$, then the MC material cannot remove them.

\section{Acknowledgements}

This project is supported by the opening foundation of the State Key Laboratory of Inorganic Synthesis and Preparative Chemistry (2011) (Number 2012-29)

\section{REFERENCES}

1. Qiu M, Qian C, Xu J, Wu J and Wang G (2009) Studies on the adsorption of dyes into clinoptilolite. Desalination 243(1-3): 286-292.

2. Wang S and Peng $Y$ (2010) Natural zeolites as effective adsorbents in water and wastewater treatment. Chemical Engineering Journal 156(1): 11-24.

3. Kallo D (2001) Applications of natural zeolites in water and wastewater treatment. Reviews in Mineralogy and Geochemistry 45(1): 519-550.

4. Elaiopoulos K, Perraki T and Grigoropoulou E (2010) Monitoring the effect of hydrothermal treatments on the structure of a natural zeolite through a combined XRD, FTIR, XRF, SEM and $\mathrm{N}_{2}$-porosimetry analysis. Microporous and Mesoporous Materials 134(1-3): 29-43.

5. Li M, Zhu X, Zhu F et al. (2011) Application of modified zeolite for ammonium removal from drinking water. Desalination 271(1-3): 295-300.

6. Liu J, Su Y, Li Q, Yue Q and Gao B (2013) Preparation of wheat straw based superabsorbent resins and their applications as adsorbents for ammonium and phosphate removal. Bioresource Technology 143(3) 32-39.

7. Bilici Baskan M and Pala A (2011) Removal of arsenic from drinking water using modified natural zeolite. Desalination 281(20): 396-403.

8. Faghihian $\mathrm{H}$ and Kabiri-Tadi M (2010) Removal of zirconium from aqueous solution by modified clinoptilolite. Journal of Hazardous Materials 178(1-3): 66-73.

9. Li T, Gu W and Lin H (2004) Property analysis of active carbon and zeolite \& preparation and application of a new type of mesoporous absorbent. China Non-metallic Mining Industry Herald 44(6): 49-52.
10. Li T, Lin $\mathrm{H}$, Song $\mathrm{C}$ and $\mathrm{Xu} Y$ (2004) Acid etching technique for preparation of mesoporous composite environmental materials. Journal of University of Science and Technology Beijing 26(3): 237-239.

11. Li T, Lin H, Song C and Gu W (2005) Application of hearting ablation technique with additive in the preparation of a new kind of mesoporous water purification material. Techniques and Equipment for Environmental Pollution Control 6(2): 36-39.

12. Li T, Lin H, Song C and Gu W (2005) Study on preparing a new kind of water purifying material by organic ion exchange-rebaking ablation process. Environmental Protection of Chemical Industry 25(1): 54-58.

13. Li T, Lin H, Song C and Cui W (2003) A new preparation method of mesoporous composite absorbent with a kind of destructive pore-making technique. China Non-metallic Mining Industry Herald 26(5): 13-16.

14. Fang K (1999) Study on microstructure of powder particle by TEM. China Powder Science and Technology 5(5): 8-10.

15. Fang K, Zou X and Su J (2003) The characterization of nano-materials by transmission electron microscope. Modern Scientific Instruments 6(2): 15-17.

16. Liu J, Fryxell GE, Mattigod S et al. (2000) Synthesis and applications of functionalized nanoporous materials for specific adsorption. Studies in Surface Science and Catalysis 129: 729-738.

17. Li T, Yang W and Zhu W (2009) Component transformation mechanism of mesoporous composite materials studied by FTIR spectroscopy and X-ray diffraction. Journal of University of Science and Technology Beijing 31(6): 739-743.

18. Cejka J, Corma A and Zones S (2010) Zeolites and Catalysis: Synthesis, Reactions and Applications. Wiley-VCH, Weinheim, Germany.

19. Sun C, Zhang F and Cao J (2015) A 'build-bottle-around-ship' method to encapsulate ammonium molybdophosphate in zeolite Y. an efficient adsorbent for cesium. Journal of Colloid and Interface Science 455(15): 39-45.

20. Pina MP, Mallada R, Arruebo M et al. (2011) Zeolite films and membranes: emerging applications. Microporous and Mesoporous Materials 144(1-3): 19-27.

21. Na K, Choi M and Ryoo R (2013) Recent advances in the synthesis of hierarchically nanoporous zeolites. Microporous and Mesoporous Materials 166(2): 3-19.

\section{How can you contribute?}

To discuss this paper, please submit up to 500 words to the journal office at journal@ice.org.uk. Your contribution will be forwarded to the author(s) for a reply and, if considered appropriate by the editor-in-chief, it will be published as a discussion in a future issue of the journal.

ICE Science journals rely entirely on contributions from the field of materials science and engineering. Information about how to submit your paper online is available at www.icevirtuallibrary.com/page/authors, where you will also find detailed author guidelines. 